BMJ Open

Sport \&

Exercise

Medicine

\title{
Changes in pulmonary function and feasibility of portable continuous laryngoscopy during maximal uphill running
}

\author{
Mette Engan (D), ${ }^{1,2}$ Ida Jansrud Hammer, ${ }^{1}$ Trine Stensrud, ${ }^{3}$ Hilde Gundersen, ${ }^{4}$ \\ Elisabeth Edvardsen, ${ }^{5}$ Hege Havstad Clemm ${ }^{1,2}$
}

To cite: Engan M, Hammer IJ, Stensrud $\mathrm{T}$, et al. Changes in pulmonary function and feasibility of portable continuous laryngoscopy during maximal uphill running. BMJ Open Sport \& Exercise Medicine 2020;0:e000815. doi:10.1136/bmjsem-2020000815

Accepted 26 July 2020
Check for updates

C) Author(s) (or their employer(s)) 2020. Re-use permitted under CC BY. Published by BMJ.

For numbered affiliations see end of article.

Correspondence to Mette Engan; Mette.Engan@ helse-bergen.no

\section{ABSTRACT}

Objective To evaluate changes in pulmonary function and feasibility of portable continuous laryngoscopy during maximal uphill running.

Methods Healthy volunteers participated in an uphill race. Forced expiratory volume in $1 \mathrm{~s}\left(\mathrm{FEV}_{1}\right)$ and forced vital capacity (FVC) were obtained before and 5 and 10 min after finishing the race. Capillary blood lactate concentration ([BLa']) and Borg score for perceived exertion were registered immediately after the race. One participant wore a portable video-laryngoscope during the race, and the video was assessed for technical performance.

Results Twenty adult subjects participated with a mean (SD) age of 40.2 (9.7) years. Mean (SD) race duration and post-exercise [BLa”] was 13.9 (2.3) min and 10.7 (2.1) $\mathrm{mmol} / \mathrm{L}$, respectively, and the median (range) Borg score for perceived exertion was $9(5-10)$.Mean percentage change $(95 \% \mathrm{Cl}) 5$ and 10 min post-exercise in $\mathrm{FEV}_{1}$ were 6.9 (3.7 to 10.2$) \%$ and 5.9 (2.7 to 9.0$) \%$, respectively, and in FVC 5.2 (2.3 to 8.1$) \%$ and 4.7 (1.6 to 7.9 ) \%, respectively. The recorded video of the larynx was of good quality. Conclusions Maximal aerobic field exercise induced bronchodilatation in the majority of the healthy nonasthmatic participants. It is feasible to perform continuous video-laryngoscopy during heavy uphill exercise.

\section{INTRODUCTION}

Airway calibre is an important determinant of airflow and is dynamically regulated by both neural and humoral factors. ${ }^{1}$ During exercise, the lower intrathoracic airway calibre may change because of alterations in the parasympathetic/sympathetic balance, increase in circulating catecholamines and release of prostaglandins by mast cells and airway epithelial cells. ${ }^{1}$ While much is understood about control of airway calibre at rest, less is known about dynamics and control of airway calibre during exercise. $^{2}$

In non-asthmatic subjects, studies suggest that complete withdrawal of parasympathetic control of airway tone occurs during moderate exercise, resulting in either a mild or no reduction of airway resistance. ${ }^{1-6}$ Reports on
What are the new findings?

Maximal uphill running induced bronchodilatation in non-asthmatic participants.

- It is feasible to use a portable video-laryngoscope during heavy uphill running.

- Future studies should aim to determine validity and reliability of field CLE testing.

airway response to exercise are mostly done indoor in laboratory settings, conditions not necessarily able to induce the similar change in airway calibre that may occur during or after outdoor sport-specific exercise. ${ }^{7}{ }^{8}$ To our knowledge, airway response to maximal field exercise challenges in non-asthmatic subjects has not been explored. Outdoor exercise challenges on healthy nonasthmatic subjects would give valuable information on normal physiological changes in the airways.

The possibility that respiratory symptoms during exercise are caused by dysfunction in the larynx has been increasingly recognised in the last decade. ${ }^{9}$ Exercise-induced laryngeal obstruction (EILO) is a condition where closure of the laryngeal inlet impacts breathing solely during strenuous exertion but appears to be normal at rest. To determine if EILO is present, a continuous laryngoscopy during exercise (CLE) test is used and considered the 'gold standard'. 10

CLE tests are mainly done indoor on a treadmill or stationary bicycle. However, there are some reports on sports-specific CLE tests performed on a few individuals during indoor rowing, ${ }^{11}$ swimming in resistance pool $^{12}$ and during various forms of exercise, that is, running at moderate pace, cycling, stairs climbing and shuttle walking. ${ }^{13}$ These tests were successfully completed with acceptable user comfort, no adverse events and satisfactory image quality of the larynx. ${ }^{11-13}$ 
However, there has not yet been done an outdoor CLE test during strenuous exercise, neither during a competition.

In order to study pulmonary response to maximal aerobic field exercise, our primary aim was to determine the change in forced expiratory volume in $1 \mathrm{~s}\left(\mathrm{FEV}_{1}\right)$ and forced vital capacity (FVC) following a steep uphill race in non-asthmatic subjects. Secondary, we aimed to determine the feasibility of performing continuous videolaryngoscopy during exercise (CLE) during steep uphill running to explore the diagnostic opportunities for EILO.

\section{METHODS}

\section{Participants and study design}

This study was a cross-sectional and feasibility study. Twenty volunteers without current asthma attending the annual Norwegian Sports Medicine Conference in 2018 were recruited to participate in an outdoor uphill race to evaluate the change in pulmonary function immediately after a maximal aerobic exercise challenge. Ethical approval was granted by the regional ethics committee, and informed written consent was obtained from all participants.

The day before the race, all participants completed the Modified AQUA2008-Questionnaire for assessment of asthma, allergy and other respiratory disorders for athletes participating in the summer Olympic games in Beijing, August $2008^{14}$ with additional questions on inspiratory breathing symptoms. Previous asthma was defined as previous use of asthma medication in childhood/youth. Atopic disease was defined as asthma, allergic rhinitis or conjunctivitis, allergic urticaria, atopic eczema, food allergy or drug allergy ever diagnosed by a physician. Only subjects without current asthma were included in the study.

The race was in a steep trail with approximately 900 stair steps up. The length of the race was $834 \mathrm{~m}$, with an increase of 301 altitude meters and an average incline of $36 \%$. The participants were asked to complete the distance as fast as possible and had a short warm-up before start. Each individual began running at $30 \mathrm{~s}$ interval.

\section{Pulmonary function}

Pulmonary function was measured as maximal expiratory flow volume curves. Baseline and 5 and $10 \mathrm{~min}$ postexercise $\mathrm{FVC}, \mathrm{FEV}_{1}$, forced expiratory flow at $50 \%$ of exhaled FVC $\left(\mathrm{FEF}_{50}\right)$ and $\mathrm{FEV}_{1} / \mathrm{FVC}$ were obtained according to standard quality criteria. ${ }^{15}$ Two spirometry devices were used in the study: (1) the Vyntus Spiro (Vyaire GmbH, Höchberg, Germany) with bacterial filter from Medical Respiratory Devices S.L. (Madrid, Spain) and (2) Smart pft USB (Medical Equipment Europe GmbH, Hammelburg, Germany) with bacterial filter Pulmosafe V3/2 (LemonMedical GmbH, Hammelburg, Germany). The same spirometry device was used pre-exercise and post- exercise for each individual. The z-values for FVC and $\mathrm{FEV}_{1}$ were calculated by the Global Lung Function Initiative online spirometry calculator. ${ }^{16}$

\section{Blood lactate concentration and Borg score}

Elevation of capillary blood lactate concentration ([BLa $]$ ) (Lactate Scout+, EKF Diagnostic GmbH, Ebendorfer Chaussee 3, 39179 Barleben, Germany) and perceived exertion registered with Borg score $(0-10)^{17}$ were used to describe the participants exercise intensity. A $\left[\mathrm{BLa}^{-}\right]$of $\geq 8$ $\mathrm{mmol} / \mathrm{L}$ is often considered to indicate that maximal oxygen consumption is reached. ${ }^{18}$

\section{Continuous laryngoscopy during exercise}

One volunteering participant had a portable videolaryngoscope attached during the race (CMOS VideoRhino-Laryngoskope and 8402ZX monitor, Karl Storz GmbH \& Co, Tuttlingen, Germany). In the starting-area of the race, personnel familiar with the equipment inserted the video-laryngoscope in one participant's pharyngeal space after application of topical lidocaine in one nostril. The handle of the laryngoscope was attached to a special headgear and a customised Rudolph-mask held the laryngoscope in position. The monitor was placed in a small backpack carried by the participant (figure 1). The recorded video of the larynx from the continuous video-laryngoscopy was assessed for technical quality by a trained physician (HHC) familiar with indoor CLE testing and the EILO diagnosis.

\section{Data analysis}

Normally distributed data were presented as means with $\mathrm{SD}$ and skewed data as median with ranges. Intraindividual changes in spirometry values were calculated using

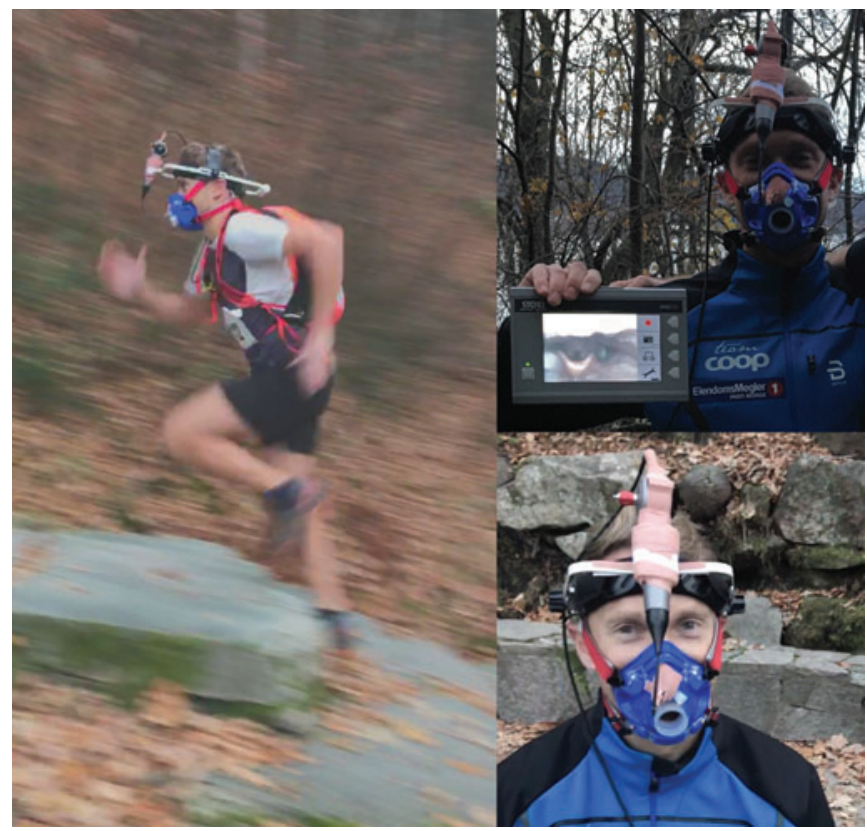

Figure 1 The participant at rest and running with the portable video-laryngoscope attached. The monitor shows the video-recording of the laryngeal area (upper right image). 
dependent Student's t-test and reported as percentage change and mean change with $95 \%$ CI.

To detect a mean difference in $\mathrm{FEV}_{1}$ of $5 \%$ with an assumed SD of $6 \%$ in a two-tailed paired t-test with an alpha value at 0.05 and a power of $90 \%$, we needed 19 participants to complete the test. ${ }^{19} \mathrm{~A} p$ value $\leq 0.05$ was considered statistically significant. Analyses were performed using IBM SPSS statistics version 24.

The feasibility of CLE testing during uphill running was determined by the time taken to mount the CLE equipment, user comfort and the recorded video's ability to visualise the larynx during the race enabling EILO assessment.

\section{RESULTS}

Characteristics of the participants and race results are presented in table 1 .

Spirometry values and changes in $\mathrm{FEV}_{1}$ and FVC from baseline to 5 and $10 \mathrm{~min}$ post-exercise are presented in table 2.

Nine participants $(45 \%)$ had an increase in $\mathrm{FEV}_{1}$ of $\geq 8 \%$, and among them, five participants $(25 \%)$ had an increase of $\geq 10 \%$ after the race. None of the participants had a decrease in $\mathrm{FEV}_{1}$ of more than $8 \%$. Six participants $(30 \%)$ had an increase in FVC of $\geq 8 \%$. The $\mathrm{FEV}_{1} / \mathrm{FVC}$ ratio increased significantly only 5 min postexercise.

The portable video-laryngoscope was mounted in less than $10 \mathrm{~min}$ and was well tolerated by the participant who was able to perform at high intensity with a [BLa'] of 12.5 $\mathrm{mmol} / \mathrm{L}$ and a Borg score for perceived exertion of 9 (very, very strong) after completing the race. The CLE video was of good quality during the field race, visualising the laryngeal movements.

\section{DISCUSSION}

To our knowledge, this is the first study to investigate changes in pulmonary function in healthy adult individuals after a short maximal aerobic field exercise. The mean increase in $\mathrm{FEV}_{1} 5$ min post-exercise was about $7 \%$ in middle-aged non-asthmatic individuals. A quarter of the participants had an increase in $\mathrm{FEV}_{1}$ of $\geq 10 \%$ and $30 \%$ of the participants had an increase in $\mathrm{FVC}$ of $\geq 8 \%$ post-exercise. A significant increase in mean $\mathrm{FEV}_{1} / \mathrm{FVC}$ ratio at $5 \mathrm{~min}$ post-exercise was observed, implying airway dilatation.

Diverging to our results, previous studies on nonasthmatic individuals in the laboratory have found that exercise induces either no change or a small decrease in airway resistance. ${ }^{1-6}$ However, in studies where the airways are pharmacological pre-constricted, exercise is shown to be a strong bronchodilator in non-asthmatic individuals. ${ }^{2} 2021$ Interestingly, similar bronchodilatation has also been reported in healthy subjects with pre-constricted airways after isocapnic hypopnea, suggesting that increased ventilation itself and not exercise induces bronchodilation. ${ }^{22}$ In our study on non-asthmatic individuals, we do not presume that the participants had an increased resting vagal tone at pre-exercise spirometry, and this could therefore not be the explanation to our findings.

Airway calibre in healthy persons shows diurnal variation, and $\mathrm{FEV}_{1}$ is shown to be lower in the morning and about $4 \%$ higher in the afternoon. ${ }^{23}$ In this study, the pre-exercise spirometry was performed in the afternoon and the postexercise spirometry was performed in the morning at about 09:00. Thus, the average increase found in $\mathrm{FEV}_{1}$ might be underestimated.

Studies on lung function after exercise of various intensity and duration report a decline in FVC, possibly explained by respiratory muscle fatigue. ${ }^{24}$ We found

Table 1 Background characteristics and race results of 20 healthy adults completing a short maximal aerobic field exercise

\begin{tabular}{|c|c|c|c|}
\hline Variables, units & & & Range \\
\hline Male gender, $\mathrm{n}(\%)$ & 17 & (85) & \\
\hline Age, years (SD) & 40.2 & (9.7) & \\
\hline BMI, kg/m² (SD) & 23.8 & (2.7) & \\
\hline Cigarette smoking, n (\%) & 0 & (0) & \\
\hline Moist snuff, $\mathrm{n}(\%)$ & 2 & (10) & \\
\hline Asthma previous, ${ }^{*} \mathrm{n}(\%)$ & 4 & (20) & \\
\hline Atopic disease, $† \mathrm{n}(\%)$ & 6 & (30) & \\
\hline Exercise $>3$ times/week, $n(\%)$ & 10 & (50) & \\
\hline Exercise daily, n (\%) & 7 & (35) & \\
\hline Ever shortness of breath/coughing during/after exercise, $n(\%)$ & 5 & (25) & \\
\hline Race time, min, mean (SD) & 13.9 & (2.3) & $10.4-19.6$ \\
\hline Lactate, mmol/L, mean (SD) & 10.7 & $(2.1)$ & $4.7-14.0$ \\
\hline Borg score perceived exertion (0-10), $\ddagger$ median & 9 & & $5-10$ \\
\hline Inspiratory stridor, n (\%) & 1 & (5) & \\
\hline
\end{tabular}

*Asthma previous defined as previous use of asthma medication in childhood/youth.

†Atopic disease defined as asthma, allergic rhinitis or conjunctivitis, allergic urticaria, atopic eczema, food allergy or drug allergy ever diagnosed by a physician.

¥Borg score grades perceived exertion from ' $0=$ nothing at all, $0.5=$ extremely weak, $1=$ very weak, $2=$ weak, $3=$ moderate, $4=$ somewhat strong, $5=$ strong, $7=$ very strong, $9=$ very, very strong, $10=$ extremely strong'. ${ }^{17}$ 


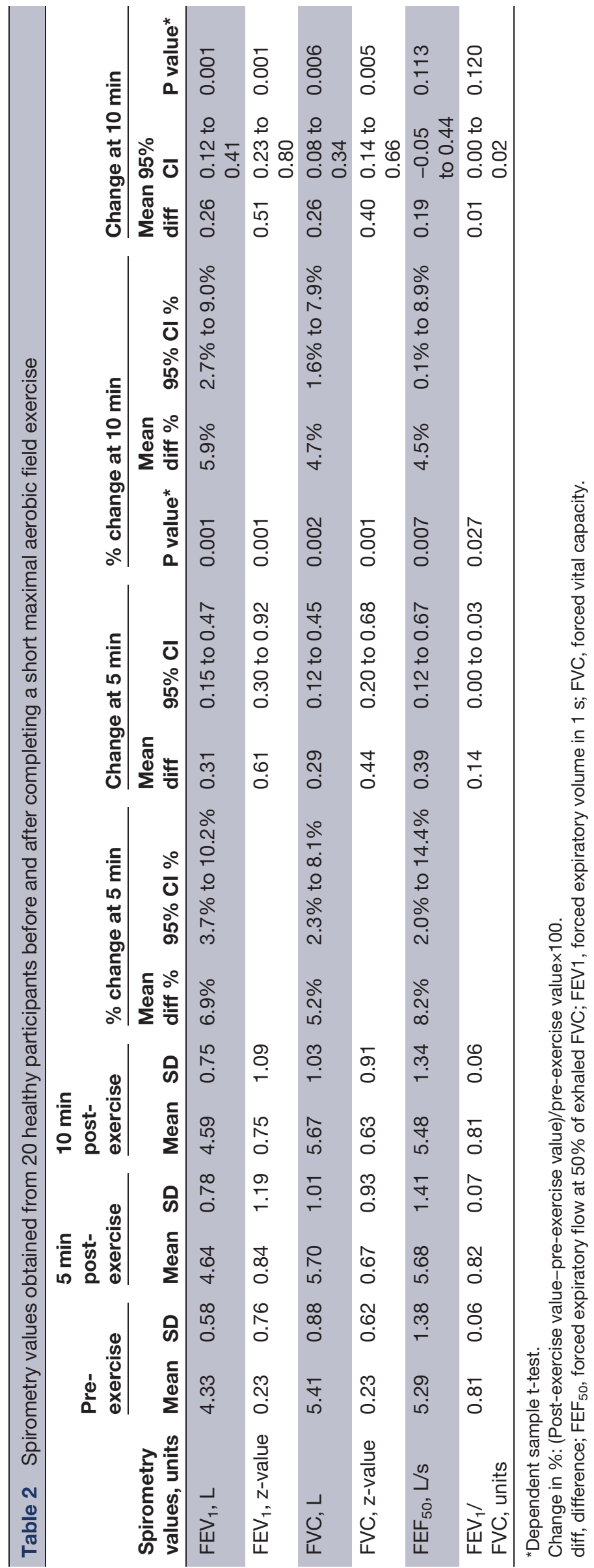


that mean FVC increased by approximately $5 \%$ after the race compared to pre-exercise values (table 2 ). We suggest that these findings represent recruitment of nonventilated lung areas and dilatation of the airways induced by the maximal aerobic exercise challenge. However, our findings need to be confirmed in future studies.

A limitation of our results on changes in pulmonary function is the small sample size with an uneven gender distribution. The recruitment was based on volunteerism and generalisation of the results should be made with caution.

The one participant wearing the laryngoscope reported not to be hampered by the equipment and performed close to his maximal effort. The recorded video was of good quality enabling clear visualisation of the larynx throughout the race. This study shows that it is possible to do a personalised CLE test to characterise laryngeal movement during outdoor sport-specific exercise like uphill running.

EILO is an important differential diagnosis when assessing respiratory symptoms during exercise with implication for treatment. ${ }^{25}$ There are a few feasibility reports on sportsspecific CLE tests performed on a few individuals. ${ }^{1-13}$ Our report is the first CLE test done outdoor during maximal effort and competition. However, the result is limited by including only one participant; thus, future studies should aim to determine the validity and reliability of ambulant CLE testing to improve diagnostic opportunities. ${ }^{13}$

\section{CONCLUSIONS}

We found that maximal aerobic field exercise induced bronchodilatation in the majority of the healthy nonasthmatic participants. Similar field studies are lacking, and our results need to be confirmed in future studies. Our study also showed the feasibility of using a portable video-laryngoscope during heavy uphill running, which is a step forward to do an advanced assessment of respiratory problems during 'real-life' exercise.

\section{Author affiliations \\ ${ }^{1}$ Department of Pediatric and Adolescent Medicine, Haukeland University Hospital, Bergen, Norway \\ ${ }^{2}$ Institute of Clinical Science, University of Bergen, Bergen, Norway \\ ${ }^{3}$ Institute of Sports Medicine, The Norwegian School of Sport Sciences, Oslo, Norway ${ }^{4}$ Department of Sport, Food and Natural Sciences, Western Norway University of Applied Sciences, Bergen, Norway \\ ${ }^{5}$ Institute of Physical Performance, The Norwegian School of Sport Sciences, Oslo, Norway}

\section{Twitter Mette Engan @EnganMette.}

Acknowledgements The authors thank Fredrik Dahlstrøm, Bjørnar Sandland Henriksen and Espen Wagener from Timik AS Norway, for providing spirometry devices and personnel to conduct the study. (Timik AS is the provider of medical technical equipment at the cardiopulmonary test laboratory at the Department of Pediatric and Adolescent Medicine, Haukeland University Hospital, and was chosen by tender).

Contributors ME and HHC conceptualised and designed the study, collected data, carried out the analyses, drafted the initial manuscript and revised the manuscript. IJH designed the data collecting instrument, collected data and reviewed and revised the manuscript for important intellectual content. TS, HG and EE conceptualised and designed the study, designed the data collection instruments, collected data and reviewed and revised the manuscript for important intellectual content. All authors approved the final manuscript as submitted and agree to be accountable for all aspects of the work.

Funding The authors have not declared a specific grant for this research from any funding agency in the public, commercial or not-for-profit sectors.

Competing interests EE received salary from GlaxoSmithKline with no potential conflicts of interest with respect to the research, authorship and/or publication of this article. The other authors have no conflicts of interest relevant to this article to disclose.

Provenance and peer review Not commissioned; externally peer reviewed.

Data availability statement $\ln$ accordance with the approvals granted for this study by The Regional Committee on Medical Research Ethics and The Norwegian Data Inspectorate, the data files are stored securely and in accordance with the Norwegian Law of Privacy Protection. All relevant data are presented in the paper. Because of the limited numbers of participants, only a subset of the data file will be made available to interested researches upon reasonable request to hege.synnove. havstad.clemm@helse-bergen.no providing Norwegian privacy legislation and GDPR are respected, and that permission is granted from The Norwegian Data Inspectorate and the data protection officer at Haukeland University Hospital.

Open access This is an open access article distributed in accordance with the Creative Commons Attribution 4.0 Unported (CC BY 4.0) license, which permits others to copy, redistribute, remix, transform and build upon this work for any purpose, provided the original work is properly cited, a link to the licence is given, and indication of whether changes were made. See: https://creativecommons.org/ licenses $/ \mathrm{by} / 4.0 /$.

\section{ORCID iD}

Mette Engan http://orcid.org/0000-0001-9740-3700

\section{REFERENCES}

1 Pichon A, Roulaud M, Denjean A, et al. Airway tone during exercise in healthy subjects: effects of salbutamol and ipratropium bromide. Int J Sports Med 2005;26:321-6.

2 Gotshall RW. Airway response during exercise and hyperpnoea in non-asthmatic and asthmatic individuals. Sports Med 2006;36: 513-27.

3 Soundariya K, Neelambikai N. Influence of exercise on pulmonary function tests in young individuals. Indian J Clin Anatomy Physiol 2015;2:181.

4 Chen WY. Reactivity of normal airways to short-term exercise. Eur $J$ Appl Physiol Occup Physiol 1978;38:277-80.

5 Backer V, Dirksen A, Bach-Mortensen N, et al. The distribution of bronchial responsiveness to histamine and exercise in 527 children and adolescents. J Allergy Clin Immunol 1991;88:68-76.

6 Beck KC, Hyatt RE, Mpougas P, et al. Evaluation of pulmonary resistance and maximal expiratory flow measurements during exercise in humans. J Appl Physiol (1985) 1999;86:1388-95.

7 Halvorsen T, Walsted ES, Bucca C, et al. Inducible laryngeal obstruction: an official joint European Respiratory Society and European Laryngological Society statement. Eur Respir J 2017;50:1602221.

8 Rundell KW, Im J, Mayers LB, et al. Self-reported symptoms and exercise-induced asthma in the elite athlete. Med Sci Sports Exerc 2001;33:208-13.

9 Price OJ, Walsted ES, Hull JH. Understanding the total airway response to exercise: current perspectives and future challenges. Current Opinion Physiol 2019;10:185-92.

10 Heimdal JH, Roksund OD, Halvorsen T, et al. Continuous laryngoscopy exercise test: a method for visualizing laryngeal dysfunction during exercise. Laryngoscope 2006;116:52-7.

11 Panchasara B, Nelson C, Niven R, et al. Lesson of the month: rowing-induced laryngeal obstruction: a novel cause of exertional dyspnoea: characterised by direct laryngoscopy. Thorax 2015;70:95-7.

12 Walsted ES, Swanton LL, van van Someren K, et al. Laryngoscopy during swimming: a novel diagnostic technique to characterize swimming-induced laryngeal obstruction. Laryngoscope 2017; 127:2298-301.

13 Hull JH, Walsted ES, Orton CM, et al. Feasibility of portable continuous laryngoscopy during exercise testing. ERJ Open Res 2019;5:00219-2018.

14 Bonini M, Braido F, Baiardini I, et al. AQUA: allergy questionnaire for athletes. Development and validation. Med Sci Sports Exerc 2009;41:1034-41.

15 Wanger J, Clausen JL, Coates A, et al. Standardisation of the measurement of lung volumes. Eur Respir J 2005;26:511-22. 
16 Quanjer PH, Stanojevic S, Cole TJ, et al. Multi-ethnic reference values for spirometry for the 3-95-yr age range: the global lung function 2012 equations. Eur Respir J 2012;40:1324-43.

17 Borg GA. Psychophysical bases of perceived exertion. Med Sci Sports Exerc 1982;14:377-81.

18 Edvardsen E, Hem E, Anderssen SA. End criteria for reaching maximal oxygen uptake must be strict and adjusted to sex and age: a cross-sectional study. PLoS One 2014;9:e85276.

19 Dhand N, Khatkar MS. Statulator: an online statistical calculator. Sample size calculator for comparing two paried means. 2014. Available http://statulator.com/SampleSize/ss2PM.htlm

20 Warren JB, Jennings SJ, Clark TJH. Effect of adrenergic and vagal blockade on the normal human airway response to exercise. Clin $\mathrm{Sci}$ 1984;66:79-85.
21 Kagawa J, Kerr HD. Effects of brief graded exercise on specific airway conductance in normal subjects. J Appl Physiol 1970;28:138-44.

22 Freedman S, Lane R, Gillett MK, et al. Abolition of methacholine induced bronchoconstriction by the hyperventilation of exercise or volition. Thorax 1988;43:631-6.

23 Goel A, Goyal M, Singh R, et al. Diurnal variation in peak expiratory flow and forced expiratory volume. J Clin Diagn Res 2015;9:CC05-7.

24 O'Kroy JA, Loy RA, Coast JR. Pulmonary function changes following exercise. Med Sci Sports Exerc 1992;24:1359-64.

25 Nordang L, Norlander K, Walsted ES. Exercise-induced laryngea obstruction-an overview. Immunol Allergy Clin North Am 2018;38:271-80. 